\title{
Adoption of NPS Fertilizer on Sorghum Crop Production by Smallholder Farmers in Gemechis and Mieso Districts of West Hararghe Zone, Oromia Regional State, Ethiopia
}

\author{
Muhammed Shako Hiko ${ }^{1}$ \\ ${ }^{1}$ Department of Agricultural Economics, College of Agriculture, Oda Bultum University, Chiro, Ethiopia \\ Correspondence: Muhammed Shako Hiko, Department of Agricultural Economics, College of Agriculture, Oda \\ Bultum University, Chiro, Ethiopia. Tel: +25-19-1223-3362. E-mail: falafidi2015@gmail.com
}

Received: January 16, 2020

Accepted: March 26, 2020

Online Published: April 15, 2020

doi:10.5539/jmsr.v9n2p46

URL: https://doi.org/10.5539/jmsr.v9n2p46

\begin{abstract}
The adoption of inorganic fertilizer such as NPS which is concerned by development clients and government is different from one farmer to another farmer and this makes productivity of agricultural crops to vary from one plot to another plot due to socio-economic, institutional and other factors. Therefore, this study was intended to know the socio-economic factors that significantly affect utilization of inorganic fertilizer NPS. Primary data was collected from 201 sampled households of selected districts. Secondary data was collected from stakeholders related with production of sorghum and inorganic fertilizer NPS in the study areas. In the sampling procedure, two stage simple random sampling was used. In the first stage, kebeles were randomly taken from total kebeles in the two districts. In the second stage, households were randomly selected from the selected kebeles. Data was analyzed using descriptive, inferential statistics and econometric models methods of data analysis. In econometric models Double Hurdle model was use to know factors affect adoption decision of inorganic fertilizer NPS and intensity use of inorganic fertilizer NPS. Double Hurdle model result confirms that district of the household, education level, family size, extension visit, expectation of the coming rainfall by the household, number of farm plot owned, total farm land owned and off/non-farm income earned by the household significantly affect adoption decision inorganic fertilizer NPS. Double hurdle model result also reveals that, district of the household, livestock holding, number of farm plot owned, participation on agricultural training by the household significantly affect intensity use of inorganic fertilizer NPS. Government and concerned stakeholders should give attention on these significant socioeconomic factors so that utilization inorganic fertilizer can be improved to sorghum crop productivity.
\end{abstract}

Keywords: Household, Inorganic Fertilizer, NPS, Sorghum and Double Hurdle Model

\section{Introduction}

Ethiopia as in most SSA countries, the yield productivity gap is huge for most crops i.e. the actual yield is below the potential yield. This demonstrates the need to intensify production including adoption of inorganic fertilizer with improved seeds coupled with good agronomic principles (Temane, 2017). Stoorvogel and Smaling (1990) estimated soil nutrient losses for the highlands of Ethiopia to be exceeding $80 \mathrm{~kg} \mathrm{~N}, \mathrm{P}_{2} \mathrm{O}_{2}$ and $\mathrm{K}_{2} \mathrm{O}$ per cultivated hectare. On the other hand, nutrient application from commercial sources amounts to only 12 percent $(10 \mathrm{~kg} / \mathrm{ha})$ of the total nutrients applied. The sources of plant nutrients for Ethiopian agriculture over the past five decades have been limited to urea and Di-ammonium Phosphate (DAP) fertilizers which contain only Nitrogen and Phosphorus that may not satisfy the nutrient requirements of crops including sorghum. In this regard however, Shiferaw (2014) reported that Ethiopian soils lack most of the macro and micronutrients that are required to sustain optimal growth and development of crops. This is exacerbated especially by Ethiopian fertilizer rates that are below international and regional standards (Agriculture Growth Program (AGP), 2013). Consequently, the yield and productivity of crops including sorghum in Ethiopia are much lower than other countries.

According to the soil fertility map made over 150 districts, Ethiopian soil lacks about seven nutrients (N, P, K, S, $\mathrm{Cu}, \mathrm{Zn}$ and B) (Ethiopian Soil Information System (EthioSIS), 2013). To avert the situation, the Ministry of Agriculture of Ethiopia has been recently introduced a new compound fertilizer (NPS) containing nitrogen, phosphorous and sulfur with the ratio of $19 \% \mathrm{~N}, 38 \% \mathrm{P}_{2} \mathrm{O}_{5}$ and $7 \% \mathrm{~S}$. This fertilizer has been currently substituted DAP in Ethiopian crop production system as main source of phosphorous (Ministry of Agriculture and Natural 
Resource (MoANR, 2013). Based on data from the 2015/16 (CSA, 2016), only 55.7 percent of the entire cropland cultivated by smallholder farmers is treated with some type of fertilizer including natural fertilizer like manure. Cereal crops like teff, maize and wheat enjoy relatively higher fertilizer application, being 76,73 and 84.4 percent of their land, respectively; whereas application on sorghum plots was even lower with 26 percent in 2015/16.

It is well known that sorghum is stable crop in Mieso and Gemechis districts in particular and in west Hararghe in general. Sorghum crop is among the selected crop in climate adaptation role since it has better ability to withstand moisture stress conditions. The use of new technologies such as inorganic fertilizer enhances productivity of agricultural crops if they are implemented appropriately and at their appropriate recommended rates. Thus, best use of inorganic fertilizers is recommended and promoted by agriculture sectors to improve the productivity at farm level. As it is known cultivation of more land is very much limited in the country in general and in west Hararghe in particular due to the critical shortage of agricultural land. One of the possible solution that supports achieving food self sufficiency is to increase the productivity of land at farm level by using agricultural inputs such as inorganic fertilizer NPS.

Farmers are utilizing inorganic fertilizer in the selected districts for this study even though the level of utilization is different from household to another household which results in variation of crop productivity along with other factors. According to planning and program section report of West Hararghe Zone of Agricultural Office (WHZAO) (2017), only $9 \%$ of the total cultivated land is covered with full extension technology packages in 2016/2017 crop year. Based on the same report, when zonal cropland area of sorghum is considered, out of total cropland of 101,960 ha covered by sorghum only 841 ha $(0.82 \%)$ was covered by improved seed with inorganic fertilizer; 12,605 ha $(12.36 \%)$ was covered by improved seed without any fertilizer; 25,144 ha $(24.66 \%)$ covered by local seed without any fertilizer; and 63,370ha (62.15\%) is covered by local seed and organic fertilizer in 2016/17 crop year (WHZAO, 2017). This shows that there are still serious problems of using important inputs such as inorganic fertilizer NPS because of different socio-economic, institutional and other factors.

Certain researches were undertaken on adoption of inorganic fertilizer; yet researches that address factors that affect adoption decision and intensity use using double hurdle model approach is limited in the study areas in particular. Therefore, this study was intended to know socio-economic and institution factors that affect the adoption of the new inorganic fertilizer NPS to work on these factors to improve the utilization of the inorganic fertilizer and contributing to the achievement of food security program.

\section{Methods}

\subsection{Description of the Study Areas}

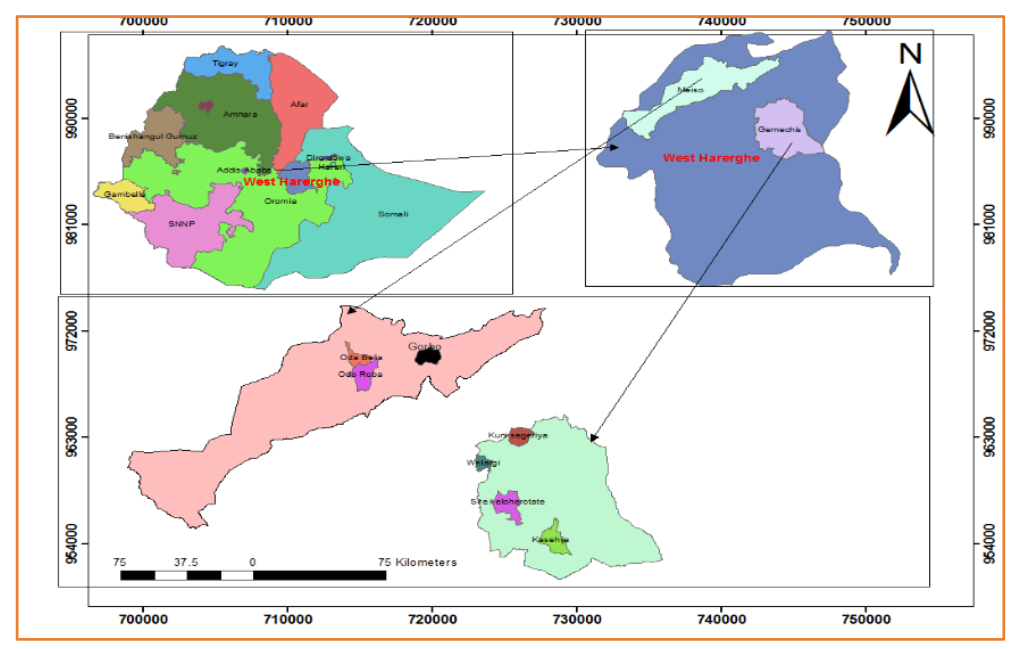

Figure 1. Location of the Study Areas

According to basic data of west Hararghe Zone of Agricultural and Natural resource office (2017), Mieso District is located at about $300 \mathrm{~km}$ from Addis Ababa to east in West Hararghe administrative zone of Oromia Regional State and $25 \mathrm{~km}$ to west of Chiro town, capital of the zone. According to the CSA (2017) population projection, the total population of the Mieso district is 144,750 out of which 82,796 and 61,954 are male and female 
respectively. The district covers an area of 186,716 ha and it has 31 rural and one urban kebeles with total of 31,456 household members in 2017.The altitude of the District is ranging from 900-2500m above sea level and average annual rainfall is about $790 \mathrm{~mm}$. The area receives a bimodal rainfall where the short rain season is between March and April while the main rain is between July and September. The economic base of the population of the district is mixed agriculture, which is crop and livestock production. The major crops grown in the district are sorghum, maize, and haricot bean. According to basic data of west Hararghe Zone of Agricultural and Natural resource office (2017) Gemechis district is one of the districts in West Hararghe zone which is located at $343 \mathrm{~km}$ east of Addis Ababa and about $17 \mathrm{~km}$ south of Chiro, capital town of the zone.The district covers an area of 77,785 ha and it has 35 rural and one urban kebeles with total of 38,700 household members.According to the CSA (2017) population projection, the total population of the district is 235,638 of which 119,485 are males and 116,153 are females in 2017. The district is found within altitude of 1300 to $2400 \mathrm{~m}$ above sea level. It receives an average annual rainfall of $850 \mathrm{~mm}$.

The district has bi-modal distribution in nature with small rains starting from March/April to May and the main rainy season extending from June to September/October. The economic base of the population of the district is mixed agriculture, which is crop and livestock production. The major crops grown in the district are maize, sorghum, groundnut, sweet potato and haricot bean. Khat, fruits and vegetables are important cash crops in the district.

\subsection{Data Types and Sources of Data}

The study was based on both primary and secondary data. It was employed primary data that was collected from the sample farm households. Primary data was collected to gather data on different social, economic and institutional variables from sample households. Secondary data such as focus group discussion and key informant interviews which are relevant were also gathered from governmental and non-governmental sources located around the study area so as to backup the primary data. These were including both published and unpublished documents.

\subsection{Sampling Technique and Sample Size}

Gemechis and Mieso districts are purposively selected for the study because it is assumed that the two districts can represent the highland, midland and lowland parts of west Hararghe zone. To determine the sample kebelesand households, a two stage random sampling procedures was used. In the first stage, numbers of kebelesout of two districts were decided according to their numbers of kebeles and randomly selected; that is probability proportional to size technique was used. In the second stage, a total of 201 numbers of sample of households from the selected kebeles of the two districts were taken and numbers of sample households per kebele were decided based on kebeles household population size (probability proportional to the size); finally households were selected randomly and interviews were undertaken. The sample size was determined based on formula provided by Cochran (1977).

To determine the required sample size at $95 \%$ confidence level, 0.5 degree of variability and $7 \%$ level of precision was used. Therefore, by using Cochran (1977) formula the sample size was;

$$
n=\frac{p q Z^{2}}{E^{2}}
$$

Table 1. Sample kebeles, agro-ecologies, total households and distribution of sample HHs

\begin{tabular}{lllll}
\hline Name of district & Name of kebele selected & Agro-ecology & Total household heads & Sample household heads \\
\hline Gemechis & Harotate & Midland & 1494 & 34 \\
& Kuni Sagariya & Highland & 1319 & 30 \\
& Kase Ija & Lowland & 1320 & 30 \\
& Walargi & Midland & 1187 & 27 \\
& Sub total & & 5320 & 121 \\
Mieso & Gorbo & Lowland & 1175 & 27 \\
& Oda Bal'a & Lowland & 1207 & 27 \\
& Oda Roba & Lowland & 1165 & 26 \\
& Sub total & & 3547 & 80 \\
& Total & & 201 \\
\hline
\end{tabular}

Source: Woreda Agricultural offices, 2019 
Where $\mathrm{n}$ is the sample size, $\mathrm{Z}$ is confidence level $(\alpha=0.05), \mathrm{p}$ is proportion of the households participating in adopting inorganic fertilizer NPS in sorghum production in the study areas and it is assumed that $50 \%(0.5), \mathrm{q}=1$ $\mathrm{p}$ and $\mathrm{E}$ is level of precision which is equal is 0.07 . The value of $\alpha$ at 0.05 confidence level is 1.96 .

Therefore, the sample size was;

$$
\mathrm{n}=(0.5 \times 0.5)(1.96)^{2} /(0.07)^{2}=196
$$

The formula suggests that 196 sample households should be taken. However, 201 sample households were taken for the study.

\subsection{Methods of Data Collection}

Based on interview scheduled primary data was collected by employing a semi-structured questionnaire modified after conducting an informal survey. Pretesting was undertaken on 10 households to correct the questionnaires before formal survey was started. Trained enumerators were used to gather data on different social, economic and institutional variables from sample households. Focus group discussions and key informants' interviews were also made with farmers, development agents, concerned agricultural professionals and administration offices by the researchers with selected woredas concerned experts and households incorporated from different social groups such as influential persons, members from different cooperatives, women and youths.

\subsection{Methods of Data Analysis}

To address the objectives of the study, descriptive and inferential statistics and econometric models of data analysis methods were employed. The statistical software package tool, Stata12 was employed in the estimation of descriptive statistics and econometric models.

In the descriptive and inferential statistics simple measures of central tendencies and variations, frequency, mean, chi-square test, t-test and percentages were used to assess household characteristics. On the econometric analyses, a Double Hurdle Model was used to know the determinants of adoption decision and intensity use of inorganic fertilizer NPS on the production of sorghum.

Different researchers used different models for analyzing the determinant of technology adoption. In principle, the decisions on whether to adopt and how much to adopt can be made jointly or separately (Berhanu and Swinton, 2003). The Tobit model was used to analyze under the assumption that the two decisions are affected by the same set of factors (Greene, 2003). Tobit is an extension of the Probit model and it is one approach to deal with the problem of censored data (Johnston \& Dinardo, 1997).

In the double-hurdle model, on the other hand, both hurdles have equations associated with them, incorporating the effects of farmer's characteristics and circumstances. Such explanatory variables may appear in both equations or in either of them (Teklewold et al., 2006). Empirical studies have also indicated that a variable appearing in both equations may have opposite effects in the two equations. The double-hurdle model, developed by Cragg (1971), has been extensively applied in several empirical studies such as Burton et al. (1996), Newman et al. (2001), Berhanu and Swinton (2003) and Teklewold et al. (2006).

Most of the previous fertilizer adoption studies that modeled intensity of inorganic fertilizer use employed a Tobit regression model, which presupposes no sample selection problem. In the presence of self-selection, however, results of Tobit model are biased and inefficient (Winship and Mare, 1992; Vella, 1998). The Tobit model assumes that a variable that affects the probability of adoption will also affect the mean amount of inputs used (Lin and Schmidt, 1984; Green, 2000). In analyzing the data, the double hurdle model was used due to its advantage over the other models such as linear probability models as it reveals both the probability of willingness to adopt and intensity of adoption (Terefe et al., 2013). It also controls the reciprocal relationship (dual endogeneity) between the two factors; adoption decision and use intensity (Ketema and Bauer, 2011).

\section{Double Hurdle Model (Craggit Model)}

The model was first proposed by Cragg (1971) to allow for two independent processes within the analytical framework. Therefore, a positive observable use of inorganic fertilizer is dependent on both the decision of the household to use/adopt and the observed intensity of use. The first process is the decision to adopt, and which has a dichotomous variable as dependent variable. The second process measures extent of use. While the first process is similar to a Probit analysis is used to model the decision to adopt, a truncated regression the model determines the extent of use of inorganic fertilizer NPS. The double hurdle model is seen as an improvement to both the Tobit and the generalized Tobit (Heckit models) (Cragg, 1971; Eakins, 2013).The Craggit (double hurdle) model specifically allows the factors that determine the adoption and level of use to differ an independent double hurdle model. Following Adeyemo and Salman (2016), the independent double hurdle model is specified as follows: 
A. The Adoption Equation**

$$
d_{i}^{*}=z_{i}{ }^{\prime} \alpha+\mu
$$

Where;

$$
d_{i}=\left\{\begin{array}{c}
1, \text { if } d^{*}>0 \\
0, \text { Otherwise }
\end{array}\right.
$$

B. The Extent of Use

$$
y_{i}^{*}=x \beta+V_{i}
$$

C. The observed/positive use of inorganic fertilizer

$$
y-d_{i} y_{i}{ }^{*}
$$

Where, $d_{i}$ is the decision to adopt and $y_{i}{ }^{*}$ is the extent of use of inorganic fertilizer used; $\mathrm{y}$ is the observed use of inorganic fertilizer NPS input use which is a function of both the decision to adopt and the extent of use. Also, $\mu$, is the error term associated with the adoption decision and $v_{i}$ is the error term associated with the extent of use equation. Thus, a positive use of inorganic fertilizer input is observed if the household decides to adopt and also use it. Independence is achieved when the following is obtained with regards to the error terms of equations 1 and 3 , when $\mu_{i} \sim N(0,1), v_{i} \sim N(0, \sigma)$.

That is, there is no correlation between the two error terms. The independent double hurdle model is estimated by maximum likelihood as follows:

$$
\log L=\left[1-\varphi\left(z_{i} \alpha\right) \varphi\left(\frac{x_{i}{ }^{\prime} \beta}{\sigma}\right)\right]+\sum_{+} \ln \left[\varphi\left(z_{i}^{\prime} \alpha\right) \frac{1}{\alpha} \varphi\left(y_{i}-x_{i} \beta\right)\right]
$$

If $z_{i} \alpha=1$ then there is no zero adoption and in fact we have a Tobit model, which just estimates the extent of use of the adoption. Where, $z_{i}$ is the vector of socio economic characteristics and other factors that determine the choice of adoption of inorganic fertilizer input method among the respondents; $x_{i}$ is the vector of socioeconomic characteristics and other factors that determine the extent of use of the inorganic fertilizer NPS adopted; $\alpha$ and $\beta$

\begin{tabular}{|c|c|c|c|}
\hline No. & Variable & Measurement & Hypothesis of relationship \\
\hline 1. & Age of the household head & Continuous & + \\
\hline 2. & Administrative or social position of the household head & Dummy & + \\
\hline 3. & Sex of the household head & Dummy & - \\
\hline 4. & Household family size & Continuous & + \\
\hline 5. & Education level of the household head & Continuous & + \\
\hline 6. & Frequency of extension visit & Continuous & + \\
\hline 7. & The agro-ecological location & Categorical & - \\
\hline 8. & District & Dummy & - \\
\hline 9. & Distance of the plot from the residence & Continuous & - \\
\hline 10. & Livestock holding (TLU) & Continuous & + \\
\hline 11. & Off/non-farm income & Continuous & + \\
\hline 12. & HH Perception of Expectation on rainfall distribution in the coming crop year & Dummy & + \\
\hline 13. & Credit received and utilized & Continuous & $+/-$ \\
\hline 14. & Market access & Continuous & + \\
\hline 15. & Number of plots & Continuous & - \\
\hline 16. & Plot area & Continuous & + \\
\hline 17. & Farmers' training & Dummy & + \\
\hline
\end{tabular}
are parameters to be estimated. This study carried out its empirical analysis on the assumption that the decision to adopt and the extent of use of inorganic fertilizer NPS are independent of each other.

\subsection{Variables Definition and Working Hypothesis}

Table 2. Summary of independent variables and their hypothesis 
Use of inorganic fertilizer (Y): The use of inorganic fertilizer refers to application of available and supplied commercial fertilizer by the local government. The commonly used inorganic fertilizers in the study areas are NPS Boron, NPS Zink, NPS Boron Zink, NPS blend, Potassium, and urea. It takes the value "1" if one or more of NPS type of inorganic fertilizers are used; and " 0 " otherwise. Question is followed by how much NPS fertilizer the household used in the study year on sorghum plot if the response is positive to know the intensity in the study year. The intensity of use of inorganic fertilizer NPSwas analyzed using second hurdle model result for the households used inorganic fertilizer NPS in kilo-gram in the production of sorghum in the study areas.

The independent variables expected to have association with the use of NPS fertilizer in the production of agricultural crops like sorghum were selected based on available literature. Based on this, 17 variables were selected. Out of 17 variables, 11 continuous/discrete and 6 dummy variables were selected as independent variables.

\section{Result and Discussions}

\subsection{Socio-Economic and Demographic Characteristics of Sample Households}

Table 3. Age, family structure and of sample HHs during the 2017/18 production year

\begin{tabular}{|c|c|c|c|c|c|}
\hline \multirow[t]{2}{*}{ Variable description } & \multicolumn{3}{|c|}{ Mean } & \multirow[b]{2}{*}{ Std. } & \multirow[b]{2}{*}{ t-statistic } \\
\hline & Gemechis & Mieso & Both & & \\
\hline Age & 42.59 & 40.62 & 41.81 & 9.57 & 1.43 \\
\hline Family size & 6.89 & 7.41 & 7.09 & 2.32 & -1.55 \\
\hline Adult equivalent & 5.20 & 5.59 & 5.36 & 1.60 & -1.60 \\
\hline Man equivalent & 2.87 & 2.59 & 2.77 & 1.07 & $1.88^{*}$ \\
\hline Education level & 1.80 & 2.43 & 2.05 & 2.86 & -1.54 \\
\hline Livestock holding (TLU) & 2.87 & 4.39 & 3.47 & 2.44 & $-4.53 * * *$ \\
\hline Cultivated land (ha) & 0.47 & 1.16 & 0.74 & 0.49 & $-13.38 * * *$ \\
\hline Homestead area (ha) & 0.029 & 0.136 & 0.072 & 0.096 & $-9.24 * * *$ \\
\hline Grazing land (ha) & 0.044 & 0.054 & 0.048 & 0.187 & -0.36 \\
\hline Forest land (ha) & 0.052 & 0.006 & 0.034 & 0.127 & $2.55^{* *}$ \\
\hline Totalfarm land (ha) & 0.58 & 1.46 & 0.93 & 0.72 & $-10.60 * * *$ \\
\hline Home to plot average distance (minutes) & 12.81 & 26.97 & 18.44 & 15.98 & $-6.81 * * *$ \\
\hline Number of plots & 1.42 & 1.58 & 1.48 & 0.59 & $-1.95 *$ \\
\hline Farming experience (years) & 25.25 & 20.27 & 23.27 & 10.48 & $3.38 * * *$ \\
\hline Total cultivated land (Ha.) & 0.519 & 1.397 & 0.865 & 0.76 & $-10.78^{* * *}$ \\
\hline Maize (На.) & 0.125 & 0.395 & 0.232 & 0.27 & $-7.79 * * *$ \\
\hline Sorghum (Ha.) & 0.25 & 0.917 & 0.515 & 0.45 & $-14.93 * * *$ \\
\hline Other crops (Ha.) & 0.016 & 0.003 & 0.012 & 0.043 & $2.15 * *$ \\
\hline Vegetables (На.) & 0.033 & 0 & 0.020 & 0.06 & $3.98^{* * *}$ \\
\hline Khat (Ha.) & 0.066 & 0.006 & 0.0422 & 0.097 & $4.48^{* * *}$ \\
\hline NPS & 27.24 & 8.75 & 19.88 & 27.63 & $4.90 * * *$ \\
\hline Urea & 10.51 & 4.53 & 8.13 & 17.39 & $2.41 * * *$ \\
\hline Farm yard manure(Qn.) & 10.89 & 4.57 & 8.38 & 12.87 & $3.5^{* * *}$ \\
\hline
\end{tabular}

Note: ${ }^{* * *},{ }^{* *}$ and $*$ represents significant at $1 \%, 5 \%$ and $10 \%$ probability level respectively.

Source: Own computation (2019).

Note. Khat (Catha edulis) is a plant with psychoactive properties, and the leaves and shoots are chewed for this effect. Khat is considered a "natural amphetamine" containing amphetamine-like stimulant substances such as cathinone and cathine (Kalix, 1992).

The average family size for the sample households was about 7.09 persons and ranging between of 2 and 15 persons. The average age of the sample household heads was 41.81 years with a maximum of 75 and a minimum of 22 years. Table 3 also shows that, on average, 2.77 out of 5.36 adult equivalents can provide labor force in man equivalent and actively engage in an economic activity. Average education level of the household was 2.05 years of schooling. The average area of cultivated, homestead, grazing and forest land by the sample households of the two districts was $0.74,0.072,0.048$ and 0.034 hectares, respectively. The average land size of the household is 0.924 hectares. The average number of plots of the sampled households during the survey period was greater than one in number, i.e. 1.48 in average. On average, the farm plots of the households take 18.44 walking minutes from 
the residence of the households. The average livestock holding was 3.47 tropical livestock unit (TLU). The mean area allocated land for total cultivated land, maize, sorghum, other crops, vegetables and Khat (Catha edulis) was $0.865,0.232,0.515,0.0112,0.02$ and 0.0422 hectares respectively. This shows that, from the total cultivated land sorghum takes largest part of the cultivated land in the study areas. Average level of use of fertilizer NPS and Urea used by the sample households was $19.88 \mathrm{Kgs}$ and $8.13 \mathrm{Kgs}$ respectively. Average level of use of organic fertilizer used by the sample households was 8.38 Quintals.

\subsection{Types of Inorganic Fertilizer Used by Sample Households}

Sample households used different types of inorganic fertilizers supplied by the local government to the study areas. Among the supplied inorganic fertilizer NPS and Urea are the major ones. From the total sample household respondents $55.72 \%$ did not use any kind of inorganic fertilizer. When we compare the two districts $82.5 \%$ of sample households of Mieso district household did not used any kind of fertilizer as this district has unfavorable agro-ecology for crop production and low annual rainfall distribution.

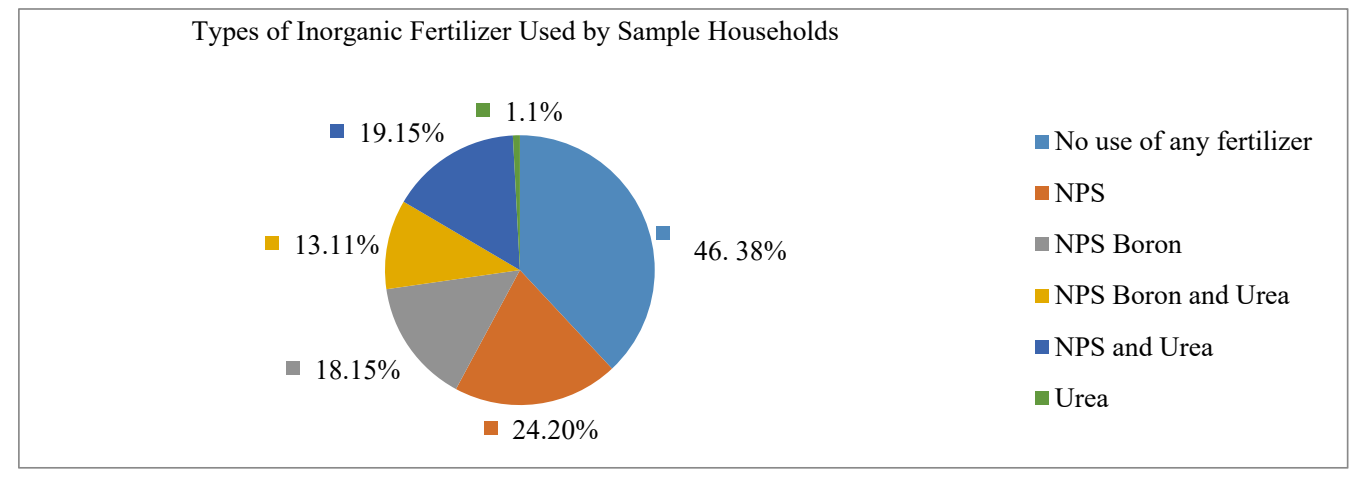

Figure 2. Types of Inorganic Fertilizer Used by Sample Households

\subsection{Amount of Inorganic Fertilizer Used on Major Crop}

The interview survey result shows that, $43.41 \%$ of inorganic fertilizer was used for sorghum production. As major land is allocated for sorghum production, more amount of inorganic fertilizer was also used for sorghum production. However, in Mieso district more inorganic fertilizer was allocated for other crops such as maize, haricot bean and other crops. Khat production also consumed more amount of inorganic fertilizer. Khat consumed around $18 \%$ of the total inorganic fertilizer used by sample household respondents in the study years.

\subsection{Econometric Result Analysis}

To determine the major factors affecting adoption and use intensity of inorganic fertilizer NPS, Cragg's double hurdle model was employed. Before executing the final analysis, preliminary analysis involving likelihood ratio (LR) test was carried out to check for superiority of the double hurdle model over the independent Tobit model. The results showed that, the restricted Tobit model should be rejected in favor of unrestricted (double hurdle model) to analyze the use intensity of inorganic fertilizer NPS. Multi-collinearity was also checked among the explanatory variables using variance inflation factors (for continuous variables) and contingency coefficients (for categorical variables). The results showed that multi-collinearity was not a serious problem among both continuous and categorical explanatory variables. Therefore, the employed model was the most robust and complete.

\subsubsection{Determinants of Adoption Decision of Inorganic Fertilizer}

Double hurdle model was regressed for 17 explanatory variables to know factors affect adoption of NPS fertilizer on sorghum crop production. Adoption of NPS fertilizer is taken as dependent variable to know factors affecting it on sorghum crop production in the study areas on the first result of double hurdle model. Adoption of inorganic fertilizer NPS increases productivity of agricultural crops agricultural crops in general and sorghum crop production in particular. Among the seventeen (17) explanatory variables, eight (8) of them significantly affect adoption decision of NPS fertilizer on sorghum crop production in the study areas.

The variable district negatively and significantly affects use of NPS fertilizer at $1 \%$ significance level of probability on sorghum crop production. This means that, when we move from Gemechis to Mieso district the probability of using inorganic fertilizer decline. In other words, household farmers in Gemechis district adopt inorganic fertilizer 
than Mieso district. The use of inorganic fertilizer is different from one district to another district because of different factors. It is well known that, Mieso district is found in lowland agro-ecology, while Gemechis district is partly found in midland and highland agro-ecologies. Thus, farmers in midland and highland agro-ecology have more conducive environment and better rainfall amount and distribution than lowland areas. Therefore, farmers in highland and midland agro-ecology district areas adopt and use more amount of inorganic fertilizer than farmers in lowlands agro-ecologies.

Table 4. Inorganic fertilizer used on the major crops by the sample HHs (2017/18 cr. yr.)

\begin{tabular}{lcccccc}
\hline \multirow{2}{*}{ Major crops } & \multicolumn{2}{c}{ Gemechis } & \multicolumn{2}{c}{ Mieso } & \multicolumn{2}{c}{ Both } \\
& Amount (Kgs) & \% share from total & Amount (Kgs) & \% share from total & Amount (Kgs) & \% share from total \\
\hline Sorghum & 2141 & 46.69 & 300 & 28.92 & 2441 & 43.41 \\
Other crops & 1081.5 & 23.58 & 662.5 & 63.86 & 1744 & 31.01 \\
Vegetables & 427 & 9.31 & 0 & 0.00 & 427 & 7.59 \\
Khat & 936.5 & 20.42 & 75 & 7.23 & 1011.5 & 17.99 \\
Total & 4586 & 100 & 1037.5 & 100 & 5623.5 & 100 \\
\hline
\end{tabular}

Source. Own Survey (2019)

Table 5. Summary of Dependent and Independent Variables

\begin{tabular}{|c|c|c|c|c|c|c|c|c|c|}
\hline No. & Types of Variables & Unit & Mean & Sd. & Total number Users & $\%$ & \multicolumn{2}{|c|}{ Total Number of Non Users } & $\%$ \\
\hline 1. & Inorganic fertilizer use & Kg. & 28.002 & 40.36 & 89 & 44.82 & 112 & & 55.72 \\
\hline \multicolumn{10}{|c|}{ Independent Variables (Continuous Variables) } \\
\hline No. & Types of Variables & & & & Unit & Minimum & Maximum & Mean & Sd. \\
\hline 1. & Age of the household & & & & Year & 22 & 82 & 42.08 & 9.94 \\
\hline 2. & \multicolumn{4}{|c|}{ Level of education of the household } & Years of sch. & & 11 & 2.05 & 2.86 \\
\hline 3. & \multicolumn{4}{|c|}{ Family size of the household } & Man eq. & & 7.8 & 2.77 & 1.06 \\
\hline 4. & \multicolumn{4}{|c|}{ Frequency of extension contact with the $\mathrm{HH}$} & Freq. of visit & & 52 & 19.06 & 14.33 \\
\hline 5. & \multicolumn{4}{|l|}{ Distance of the farm plot } & Minutes & & 90 & 18.44 & 15.98 \\
\hline 6. & \multicolumn{4}{|c|}{ Livestock holding of the household } & TLU. & & 17.96 & 3.47 & 2.44 \\
\hline 7. & \multicolumn{4}{|c|}{ Off-farm income of the household } & Birr & & 20000 & 775.12 & 2393.75 \\
\hline 8. & \multicolumn{4}{|c|}{ Credit received and utilized } & Birr & & 10000 & 170.64 & 1045.55 \\
\hline 9. & Average market distan & & & & Minutes & & 225 & 80.39 & 41.49 \\
\hline 10. & Number of farm plots & ned by & he $\mathrm{HH}$ & & No. & & 3 & 1.48 & 0.59 \\
\hline 11. & Total farmland owned & the ho & ehold & & Hectare & & 5.25 & 0.936 & 0.72 \\
\hline & & & Indepe & ndent $\mathrm{V}$ & riables (Dummy Var & & & & \\
\hline No & Type of variables & & & & Male & $\%$ & Female & & $\%$ \\
\hline 1. & Sex of the household he & & & & 174 & 86.57 & 27 & & 13.43 \\
\hline 2. & District of the househol & & & & Gemechis & $\%$ & Mieso & & $\%$ \\
\hline & & & & & 121 & 60.20 & 80 & & 39.80 \\
\hline 3 & Responsibility of the $\mathrm{H}$ & heads & & & No responsibility & $\%$ & Has resp & ibility & $\%$ \\
\hline & & & & & 122 & 60.70 & 79 & & 39.30 \\
\hline 4 & Agro-ecology of the HF & ves & & & Highland /Midlan & $\%$ & Lowland & & $\%$ \\
\hline & & & & & 91 & 45.27 & 110 & & 54.73 \\
\hline 5 & Expectation about the $\mathrm{c}$ & ing $\mathrm{RF}$ & distribution & & Better & $\%$ & $\mathrm{Bad}$ & & $\%$ \\
\hline & & & & & 93 & 46.27 & 108 & & 53.73 \\
\hline 6 & Participation on trainin & $y$ the $H$ & & & Participated & $\%$ & Did not & icipated & $\%$ \\
\hline & & & & & 76 & 37.81 & 125 & & 62.19 \\
\hline
\end{tabular}

Source. Own computation (2019).

Note. HH is Household and RF is Rainfall.

The variable level of education negatively affects adoption decision of NPS fertilizer at $10 \%$ significance level on sorghum crop production. It means that, as the level of education increase the probability of adoption of inorganic fertilizer decline. This contrasts to the hypothesis of the research. The implication of the result may be educated household may compare the comparative advantage of substitutable inputs like organic fertilizer and inorganic 
fertilizer and prefer the better one. Again in the rural areas most the youths who are educated are have small areas of land on which they may use input technologies.

The other variable which affects adoption of the inorganic fertilizer is household family size. Household family size positively and significantly affects use of inorganic fertilizer at $1 \%$ significance level of probability. This means, households with more family size have more probability of using inorganic fertilizer than those households with smaller family size on sorghum crop production. The result is in line with the hypothesis of the research. The result might be due to household with more labor force have the probability of building more asset when compared to household with lesser labor force. Thus, those households with more labor create more assets and income can afford the increasing price of inorganic fertilizer. This result is also similar with that of Hassen et al. (2012), Nega (2003) and Teame (2011).

Other factor which affects use of inorganic fertilizer use is frequency extension visit to household farmer visited by the development agent. The result of Double hurdle model reveals that, frequency of extension visit positively affects use of inorganic fertilizer at $5 \%$ significance level on sorghum crop production. This means when frequency of extension visit increase probability of using NPS fertilizer also increases. The results of Wagayehu and Drake (2003), Beshir et al. (2012) and Umeh and Exewenge (2017) are similar with this finding. However, the results of finding of Degefu and Mengistu (2017) contrasted with this finding.

Expectation of household on the coming rainfall from bad to the better positively affects use of inorganic fertilizer at $1 \%$ significance level. This means that, as household perception is positive toward the coming rainfall distribution, the probability of decision to use inorganic fertilizer become increase. Rural household farmer forecast about the coming rainfall distribution based on the temporary weather condition of their areas. Thus, the positive or negative expectation of the farmer household has impact of on using inorganic fertilizer. Nega's (2003) study is also similar with this finding.

Table 7. Determinants of inorganic fertilizer adoption decision and use of intensity

\begin{tabular}{|c|c|c|c|c|}
\hline \multirow{3}{*}{ Explanatoryvariables } & \multicolumn{4}{|c|}{ Use of inorganic fertilizer (NPS) } \\
\hline & \multicolumn{2}{|c|}{ Adoption Decision } & \multicolumn{2}{|c|}{ Use of Intensity } \\
\hline & Coefficient & Standard Error & Coefficient & Standard Error \\
\hline Sex & 0.316 & 0.387 & 4.051 & 7.996 \\
\hline Age & 0.004 & 0.015 & -0.142 & 0.336 \\
\hline District & $-1.860 * * *$ & 0.628 & $34.425^{* *}$ & 14.478 \\
\hline Education level & $-0.106^{*}$ & 0.060 & 0.524 & 1.232 \\
\hline Household size & $0.379 * * *$ & 0.135 & 2.710 & 2.122 \\
\hline HH Responsibility & -0.161 & 0.292 & -0.547 & 5.375 \\
\hline Agro-ecology & 0.616 & 0.487 & 4.341 & 10.405 \\
\hline Frequency of extension visit & $0.025 * *$ & 0.011 & 0.315 & 0.242 \\
\hline Average distance of the plots & -0.010 & 0.011 & -0.290 & 0.271 \\
\hline Livestock holding & 0.122 & 0.077 & $4.783 * *$ & 2.077 \\
\hline Expect. $\mathrm{HH}$ about coming RF & $1.162 * * *$ & 0.333 & 0.120 & 7.418 \\
\hline Average market distance & 0.0004 & 0.004 & -0.108 & 0.098 \\
\hline Number of plots & $-0.0553 * *$ & 0.292 & $9.733^{*}$ & 5.497 \\
\hline Total farmland owned & $0.574 *$ & 0.345 & -2.700 & 6.419 \\
\hline Creditutilized (ln) & -0.019 & 0.105 & 1.027 & 1.652 \\
\hline Off/non-farm income (ln) & $0.137 * * *$ & 0.044 & -1.146 & 0.739 \\
\hline HH participation on training & -0.057 & 0.337 & $-18.058 * * *$ & 6.115 \\
\hline Constant & -0.992 & 1.014 & -22.895 & 22.030 \\
\hline Sigma & $16.839 * * *$ & 1.821 & - & - \\
\hline Number of Observations & 201 & & & \\
\hline Log likelihood & -349.405 & & & \\
\hline Wald c $c^{2}(17)$ & 57.64 & & & \\
\hline Probability $>c^{2}$ & 0.0000 & & & \\
\hline Akaike Information Criteria (AIC) & 772.810 & & & \\
\hline
\end{tabular}

Note. ${ }^{* *},{ }^{* *}$ and $*$ represents significance at $1 \%, 5 \%$ and $10 \%$ probability level respectively.

Source. Double Hurdle Model Output (2019). 
The other variable which affects adoption of NPS fertilizer was number of farm plot owned by the household. Number of farm plot owned by the household farmer negatively affects adoption of inorganic fertilizer on sorghum crop production at $10 \%$ significance level. This implies household who have more numbers farm plot have less probability of adopting inorganic fertilizer than household who owns small number of farm plot. This is in line with the hypothesis of the research. It is not convenient to manage, utilize, apply new technologies if the farm plot is scattered on different areas.

Size of farm land owned by the household positively and significantly affects adoption decision of NPS fertilize on sorghum crop production at $10 \%$ significance level. This shows that, household who has larger size farm land have more probability of adopting NPS fertilizer than household who own smaller area of land. This is because household who have large area of farm land has better advantage because of achieving economies of scale. Those farmers who have more land use more inputs than who owns less area of land because per unit cost of input is minimized.

Off/non-farm income received by the household positively affects adoption NPS fertilizer on sorghum crop production at $1 \%$ significance level. This means that, the probability of adoption inorganic fertilizer increase with increase of the household off/non-farm income received per year. Those household farmers who have better income can afford purchasing of inorganic fertilizer which its price is increasing from time to time than household farmers with lesser income.

\subsubsection{Determinants of Intensity Use of Inorganic Fertilizer}

Intensity use is the level of change in selected dependent variable with one unit change of explanatory variable by keeping other factors constant. The decision to use one new technology and the level of using that technology is may not be the same. That is why some of the variables which were significant in the first hurdle model were not significant in the second hurdle model and vice versa. The decision to adopt inorganic fertilizer is already discussed under the first result part of double hurdle model. Under this section second part of double hurdle model is discussed. In using inorganic fertilizer four variables such as district of the household, livestock holding by the household, number of the farm plot owned by the household and participation of agricultural training by the household significantly affect intensity use of inorganic fertilizer.

The second double hurdle model reveals that, district of the household positively affects intensity use of NPS fertilizer. This implies as district changes from Gemechis to Mieso district level use of inorganic fertilizer increase by $34.48 \mathrm{~kg}$ at $5 \%$ significance level keeping other factors constant. However, the decision to adopt inorganic fertilizer is in opposite direction. Intensity use of inorganic fertilizer increase in Mieso because of landholding in Mieso district is better than in Gemechis district. Farmers those hold more land and allocate more land for sorghum production. In Gemechis district large volume of inorganic fertilizer is allocated for other crops such as maize, Khat and vegetables. More sorghum is cultivated in Mieso district than Gemechis district. Thus, more amount of inorganic fertilizer is used for sorghum production in Mieso district.

The other variable that affects use of inorganic fertilizer is livestock holding by the household. Livestock holding positively affects intensity use of inorganic fertilizer on sorghum production crops. The second double hurdle model result reveals that, as the livestock holding increase by 1 TLU use of inorganic fertilizer increased by $4.78 \mathrm{~kg}$ at $5 \%$ significance level keeping other factors constant. This implies that, holding more livestock increases the capacity of the household farmer of utilizing more inorganic fertilizer on sorghum production crop. Holding more livestock solves the problem of cash constraints by the household.

Number of farm plot owned by the household positively affects intensity use of inorganic fertilizer on sorghum crop production. The second double hurdle model result reveals that, intensity use of inorganic fertilizer increases by $10.41 \mathrm{~kg}$ as number of farm plot increases by 1 keeping other factors constant. As household holds more number of farm plot utilization of more inorganic fertilizer increases. Those farmers who owns more number of plots allocates more number of farm plots for sorghum production. Thus, more amount of inorganic fertilizer is allocated for sorghum crop production.

The other variable which affects level use of inorganic fertilizer is participation of farmer household on agricultural training. The double hurdle model output reveals that, farmer who participates on agricultural training used $18.61 \mathrm{~kg}$ less than that of who do not participate on agricultural training at $1 \%$ significance level. This may be because of attention sectors on the selection of farmer who participate on agricultural training may be on other issues. It may also be selection of the farmer for training may be based on the other activity engagement of the farmer. Thus, selection of the farmer for agricultural training needs more attention to achieve the intended objectives. It needs further research to improve positive impact of agricultural training provided at different levels. 


\section{Summary, Conclusion and Recommendations}

The adoption of inorganic fertilizer which is concerned by development clients and government is different from one farmer to another farmer; this makes productivity of agricultural crops is varies from one plot to another plot and from household to another household due to socio-economic, institutional and other factors. Thus, this study attempted to identify the determinants of adoption of inorganic NPS fertilizer on sorghum crop production in Gemechis and Mieso districts of West Hararge zone of Oromia national regional state of Ethiopia.

For this study, data collected from a total of 201 sampled household heads were used. Descriptive statistics were used to know respondent farmers household characteristics. The results in descriptive statistics showed that, about $43.78 .5 \%$ and $23.38 \%$ of the farmers used NPS and urea fertilizers respectively. On average, $27.63 \mathrm{~kg}$ and $17.39 \mathrm{~kg}$ of NPS and urea fertilizers were used by the sample households respectively.

The study identified the determinants of household's decision to adopt and intensity use of inorganic fertilizer using Double Hurdle model. Double Hurdle model result confirmed that, district of the household, education level of the household, household family size, extension visit, perception of expectation of the household of distribution and amount of coming season rainfall, number of farm plot owned by the household, total farm land owned by the household and annual non/off-farm income received by the household significantly affect decision to use inorganic NPS fertilizer. The result of the double hurdle model also shows that, district of the household, livestock holding, number of farm plot owned by the household and participation of the household on agricultural training significantly affect intensity use of inorganic NPS fertilizer on sorghum crop production.

As a conclusion, in the study areas some farmers adopted NPS inorganic fertilizer. In the adoption of NPS inorganic fertilizer farmers are different because of socio-economic and demographic characteristics of household heads. The level of use of NPS inorganic fertilizer was also different. Therefore, multiple interventions are needed on significant factors such as frequency extension visit, livestock holding, annual off/non-farm income earned by the household, perception of the expectation of the coming season rainfall, number of farm plot owned by the household, total farm land owned by the household and participation of the household on agricultural training by concerned stakeholders.Analysis of cross-sectional survey data based on 201 sample households in Gemechis and Mieso districts in 2017/18 crop year showed that, farmers use inorganic NPS fertilizer and the intensity use of it was influenced by different factors such as, social, economic and institutional factors.

The results of the study identified the determinants of inorganic fertilizer use and provide information to policy makers and extension workers on how to improve farm level NPS inorganic fertilizer. This could contribute to improve inorganic fertilizer adoption and generally help agricultural production development. These findings address the need for appropriate policy formulation and implementation which enables farmers to enhance adoption of NPS inorganic fertilizer in the study areas and other similar areas of the zone and the region. On the basis of the survey results the following points were suggested.

As extension visit positively affected adoption decision to use inorganic NPS fertilizer, government should increase the coverage of agricultural extension service and better increase the ratio development agent to the household. Improving better facilities for development agent also have positive impact on adoption of new agricultural technologies. Livestock holding positively affect decision to use inorganic NPS fertilizer. Livestock holding in West Hararghe zone is limited by shortage of landholding and animal feed. Government and concerned body should work on increasing livestock holding, improving productivity of livestock and improved livestock feed as livestock holding minimize problem of cash shortage to purchase inorganic fertilizer.

Positive perception expectation of farm household has positive impact on adoption and intensity of NPS fertilizer. Therefore, government should work on providing and improving insurance system for agricultural crop to minimize impact of pessimistic attitude of farmer's household and risk of crop failure due to shortage of rainfall.

Participation of farmer on agricultural training negatively and significantly affects intensity to use inorganic fertilizer. Therefore, the concerned sector should review the capacity building system of famers on this sector. Appropriate screening system manpower for agricultural training should be undertaken. Off/non-farm income positively and significantly affects intensity to use inorganic fertilizer. Therefore, governments should work on how the income of poor farmer household farmers can be improved so that level use of inorganic fertilizer can be improved. Number of farm plot owned by the household negatively and significantly affects adoption decision of inorganic fertilizer. Government should work more on cluster farming so that farmers cooperative and merge their farm plot and use improved technologies intensively. 


\section{Conflict of interests}

The authors declare that there is no conflict of interests regarding the publication of this paper.

\section{References}

Agriculture Growth Program. (2013). From sample blended fertilizers to ample yields. Retrieved from http://ethioagp. org/from-sample-blended-fertilizers-to-ample-yields/

Berhanu, G., \& Swinton, S. M. (2003). Investment in Soil Conservation in Northern Ethiopia: The Role of Land Tenure Security and Public Program. Agricultural Economics, 29, 69-84.https://doi.org/10.1111/j.15740862.2003.tb00148.x

Burton, M., Dorsett, R., \& Young, T. (1996). Changing Preferences for Meat: Evidence from UK Household Data. 1973-1993. European Review of Agricultural Economics, 23(3), 357370.https://doi.org/10.1093/erae/23.3.357

Central Statistics Agency (CSA). (2016). Agriculture Sample Survey 2015/16 (2008 E.C.). Statistical Bulletin, Report on Area and Production of Major Crops (Private Peasant Holdings, Meher Season). Addis Ababa, Ethiopia.

Central Statistics Agency (CSA). (2017). LSMS-Integrated Surveys on Agriculture Ethiopia Socioeconomic Survey (ESS)2015/2016. A Report by the Central Statistical Agency of Ethiopia. Retrieved from http://microdata.worldbank.org/index.php/catalog/2783

Chilot, Y., \& Hassan, R. M. (2013).Determinants of Inorganic Fertiliser Use in the Mixed Crop livestock Farming Systems of Central Highlands of Ethiopia. African Crop Science Journal, 21(Supplement s3), 669681.

Cochran, W. G. (1977). Sampling Techniques (3rd ed.). New York: John Wiley and Sons, Inc. In J. H. Aldrich \& F. D. Nelson (Eds.), Linear Probability, Logit and Probit Model: Quantitative Application in the Social Science.Sage publication Inc, University of Minnesota and Iola, London.

Cragg, J. G. (1971). Some Statistical Models for Limited Dependent Variables with Application to the Demand for Durable Goods. Econometrica, 39(5), 829-844.https://doi.org/10.2307/1909582

Eakins, J. (2013). An Analysis of the Determinants of Household Energy Expenditures: Empirical Evidence from the Irish Household Budget Survey. Unpublished PhD Thesis in Economics, University of Surrey, May 2013.

EthioSIS (Ethiopian soil information system). (2013). Soil Analysis Report Agricultural Agency.

Fufa, \& Hassan. (2006). Determinants of Fertilizer Use on Maize in Eastern Ethiopia: A Weighted Endogenous Sampling Analysis of the Extent and Intensity of Adoption. Agrekon, 45(1).https://doi.org/10.1080/03031853.2006.9523732

Green, W. H. (2000).Econometric Analysis (4th ed.). New Jersey: Prentice-Hall.

Greene, W. H. (2003). Econometric Analysis (5th ed.). Macmillan, New York, USA.

Hassen, B., Bezabih, E., Belay, K., \& Jema, H. (2012). Determinants of Chemical Fertilizer Technology Adoption in North Eastern Highlands of Ethiopia: The Double Hurdle Approach. Journal of Research in Economics and International Finance (JREIF), 1(2), 39-49.

Johnston, J., \& Dinardo, J. (1997). Econometrics Methods (4th ed.). The McGraw-Hill Companies, Inc, New York, USA.

Kalix, P. (1992). Cathinone, a natural amphetamine. Pharmacol Toxicol, 70(2), 7786.https://doi.org/10.1111/j.1600-0773.1992.tb00434.x

Ketema, M., \& Bauer, S. (2011). Determinants of Manure and Fertilizer Applications in Eastern Highlands of Ethiopia. Quarterly Journal of International Agriculture, 50(3), 237-252.

Lin, T., \& Schmidt, P. (1984). A test of the Tobit specification against an alternative suggested by Cragg. The Review of Economics and Statistics, 66(1), 174-177.https://doi.org/10.2307/1924712

Minstry of Agriculture and Natural Resource. (2013). Ethiopia is transitioning into the implementation of soil test based fertilizer use syste. Retrieved from http://www.moa.gov.et/documents/93087/.../ be8d5386-e5fb-4ca3$8 \mathrm{ff0}-\mathrm{d} 295 \mathrm{bc} 603 \mathrm{e} 70$ 
Negera, E., \& Getachew, B. (2014). Factors Affecting Adoption of Chemical Fertilizer by Smallholder Farmers in Guto Gida District, Oromia Regional State, Ethiopia. Science, Technology and Arts Research Journal Sci. Technol. Arts Res. J., 3(2), 237-244.https://doi.org/10.4314/star.v3i2.31

Newman, C., Henchion, M., \& Matthews, A. (2001). Infrequency of Purchase and Double Hurdle Models of Irish Households' Meat Expenditure. European Review of Agricultural Economics, 28(4), 393419.https://doi.org/10.1093/erae/28.4.393

Shiferaw, H. (2014). Digital soil mapping: Soil fertility status and fertilizer recommendation for Ethiopian agricultural land (Conference paper). Addis Ababa, Ethiopia.

Stoorvogel, J. J., \& Smaling, E. M. A. (1990). Assessment of soil nutrient depletion in subSaharan Africa, 19832000. Report 28, DLO Winand starring Center for integrated land, soil and water research (CSC-DLO), Wageningen, Netherlands.

Tamene, L., Amede, T., Kihara, J., Tibebe, D., \& Schulz, S. (Eds.). (2017). A Review of Soil Fertility Management and Crop Response to Fertilizer Application in Ethiopia: Towards Development of Site- and Context-Specific Fertilizer Recommendation. CIAT Publication No. 443. International Center for Tropical Agriculture (CIAT), Addis Ababa, Ethiopia. Retrieved from http://hdl.handle.net/10568/82996

Teklewold, H., Legesse, D., Alemu, Y., \& Dana, N. (2006). Determinants of Adoption of Poultry Technology: A Double-Hurdle Approach. Livestock Research for Rural Development, 18(40).

Temitayo, A. A., \& Kabir, K. S. (2016). Dynamics of Observable Use of Family Planning Methods in Rural Nigeria: A Double Hurdle Model Approach. IOSR Journal of Humanities and Social Science (IOSR-JHSS), 21(12), 33-43.

Terefe, T., Ahmed, H., \& Gebremariam, G. (2013). Adoption and Extent of Use of Organic Fertilizer in Arsi Negelle District, Oromia Regional State of Ethiopia: What are the Sources? Advanced Journal of agricultural Research, 1(4), 061-071.

Tesfaye, Z., Girma, T., Tanner, D., Verkuijl, H., Aklilu, A., \& Mwangi, W. (2001). Adoption of Improved Bread Wheat Varieties and Inorganic Fertilizer by Small-Scale Farmers in Yelmana Densa and Farta Districts of Northwestern Ethiopia. Mexico, D.F.: Ethiopian Agricultural Research Organization (EARO) and International Maize and Wheat Improvement Center (CIMMYT).

Vella, F. (1998). Estimating models with sample selection bias: A survey. Journal of Human Resources, 33(1), 127-169.https://doi.org/10.2307/146317

West Hararghe Zone of Agricultural Office (WHZAO). (2017). West Hararghe Zone Agricultural Office Report of cultivated and planted land on 2016/2017 crop year.Chiro, Ethiopia.

Winship, C., \& Mare, R. D. (1992). Models for sample selection bias. Annual Review of Sociology, 18, 327350.https://doi.org/10.1146/annurev.so.18.080192.001551

\section{Copy rights}

Copy right for this article is retained by the author(s), with first publication rights granted to the journal.

This is an open -access article distributed under the terms and conditions of the Creative Commons Attribution license (http://creativecommons.org/licenses/by/4.0/). 